\title{
Efeito da viscosidade do solvente sobre a contagem de fótons em tempo de vida de fluorescência resolvida no tempo: estudos empregando a equação de Stokes-Einstein- Debye para difusão rotacional
}

\section{Mayara Cesila de Farias*, René Nome.}

\section{Resumo}

O objetivo do presente trabalho foi estudar a distribuição de Poisson aplicada ao estudo de processos estocásticos, analisando séries temporais, efeito da taxa de emissão e da heterogeneidade. Também foi realizado um estudo do efeito do tipo de ruído sobre a forma da função de correlação, para então realizar uma análise dos resultados experimentais de contagem de fótons a partir de distribuições de Poisson e funções de correlação.

\section{Palavras-chave}

Poisson, Séries Temporais, fótons

\section{Introdução}

O projeto desenvolvido visa investigar a conexão entre duas séries temporais relevantes em espectroscopia molecular: emissão e espalhamento de luz. Do ponto de vista experimental, ambos são rotineiramente medidos através de técnicas de contagem de fótons individuais. No entanto, a estatística dos dois processos é qualitativamente diferente. A emissão de luz segue uma distribuição de Poisson, enquanto que o espalhamento dinâmico é interpretado através de uma distribuição normal. Ambas as distribuições são adequadas no caso de sistemas que não exibem muitas escalas de tempo.

Concentramos nossos esforços a emissão de luz. Para estas séries temporais, que seguem umaa distribuição de Poisson, determinou-se a relação entre o limiar e taxa média de eventos associados à contagem de fótons individuais. Em seguida, foi determinado se os eventos gerados de fato obedecem à distribuição de Poisson. Finalmente, estudou-se o efeito da taxa de amostragem sobre a distribuição de Poisson.

\section{Resultados e Discussão}

Ao longo do projeto investigou-se o caso em que os histogramas não são amostrados ao longo de todo o conjunto da série temporal, mas a partir de um processo amostragem esparsa.

Especificamente, dentro do tempo de simulação, foram escolhidos elementos do vetor 'tempo' formando um subconjunto do espaço amostral completo. Esta amostragem foi realizada aleatoriamente. A partir dos dados selecionados através deste processo de amostragem, construíram-se os histogramas, os quais foram comparados com o processo de Poisson, como apresentado na Figura 4 abaixo. A partir desta análise, foi possível observar que, mesmo quando a amostragem é esparsa, a distribuição simulada é semelhante à distribuição de Poisson analítica
No contexto da espectroscopia de fluorescência, este é um resultado de extrema importância, uma vez que a contagem de fótons realizada experimentalmente assume que apenas um subconjunto do número total de fótons emitidos é detectado. Isso se deve ao fato de que a emissão de fótons é tridimensional, enquanto que a detecção é comumente realizada ao longo de uma direção somente.

${ }^{1}$ MORETTIN, P.A. \& TOLOI, C.M. (2004) - Análise de Séries Temporais. Edgar Blucher Ltda. São Paulo.

2FISCHER, SÉRGIO (1982) - Séries Univariantes de Tempo - metodologia de Box e Jenkins. Porto Alegre, FEE.

3ZZEVALLOS, MAURICIO (2015) - Notas de aula sobre Séries Temporais. Campinas. 